\title{
Obituary.
}

Sir William B. Leishman, K.C.M.G., C.B., F.R.S. THE death of Sir William Leishman after a brief illness is one that will be widely and keenly felt in many circles, scientific and military, and not least by the corps to which he had given a lifelong devotion and to whose headship he had attained by sheer merit and force of personality three years before his death. His decease also breaks the circle of Service officers whose labours have opened up new ground in tropical medicine.

A medical graduate of Glasgow, Leishman entered the medical service of the army in I887, but it was not until ten years later that the call to the laboratory life came to him and we find him installed at Netley at the feet of Sir Almroth Wright and Sir David Semple. With Semple's removal to India in Igoo, Leishman became assistant professor of pathology, and in 1903 , with the disbandment of the Netley laboratory, he came to London to be professor of pathology at the Royal Army Medical College, a post he retained until I9I3. The War gave Leishman abundant scope for his administrative qualities, particularly in the organisation and supervision of bacteriological services in France, which proved such indispensable units in the general scheme of military medicine and hygiene. When the Director-Generalship of the Army Medical Service became vacant in 1923 , it was pleasant news to many that one whose reputation rested on his achievements as a scientific worker and teacher had been raised to this important post, which, we believe, Leishman was filling with great acceptance when the end came.

It is appropriate here to refer mainly to Leishman's scientific labours, two at least of which have made his name a household word in medical science. These were his modification of the Romanowsky staining procedure in Igor and his description for the first time in 1903 of the Leishman-Donovan bodies, the specific protozoal agent of kala-azar and tropical sore and other forms of leishmaniasis which have since become known.

The method of Romanowsky staining, now so indispensable an aid to parasitological and hæmatological technique, was, when first introduced, a cumbrous and perhaps somewhat uncertain procedure. Leishman conceived the idea of securing in one stain the product obtained by the interaction of methylene blue and eosin and dissolving that product in methyl alcohol. This solution both fixed and stained the preparation at the same time, and by the addition of distilled water at a certain stage in the process, a picture was obtained in which the chromatin material present took up the characteristic Romanowsky tint.

Leishman's stain gained wide fame and use and is still largely employed, though for certain purposes modifications such as that of Giemsa are preferred. It was admittedly the use of Romanowsky staining in the form modified by himself which enabled him to obtain a clearer picture of the structural details of the curious bodies the real nature of which had perplexed him for three years. These bodies he had observed first in spleen smears from a fatal case of obscure splenomegaly invalided from Dum-Dum, near Calcutta, to Netley. That they were protozoal para- sites he had no doubt when he finally published his description of them in 1903, and he hazarded the opinion, based on observations of the forms assumed by trypanosomes in the blood and organs of rats which had died of experimental Nagana infection, that the bodies pointed to the presence of trypanosomiasis in India-or at least some form of trypanosomiasis in which the fully-developed trypanosome might only rarely make its appearance in the blood stream.

The description by Leishman appeared in May 1903. and in July came an announcement from Donovan confirming Leishman's observations in certain cases of obscure splenomegaly in Madras. Shortly afterwards was reported the finding of similar bodies in tropical sore (Delhi boil) and in the disease known as kala-azar in Assam. Kala-azar, in fact, was proved, by the finding of the parasite, to have other foci outside its main home in Assam.

The writer of this notice may be pardoned for alluding to the finding of these bodies by Marchand and him in the organs of a German soldier returned from the Boxer campaign who died in a Leipzig hospital in December 1902. In their description by Marchand in March 1903 , the only opinion that was hazarded was that the bodies might represent some unique form of nuclear degeneration of spleen cells in the obscure symptom-complex known as splenic anæmia-an opinion that was promptly revised when the communications of Leishman and Donovan came to their knowledge later in the year. The Leipzig case pointed to the presence of kala-azar in China, since then a wellrecognised centre.

Leishman's view that the Leishman-Donovan bodies represented some form of trypanosomiasis had much to be said for it, and the subsequent discovery by Rogers that flagellate trypanosome-like forms developed from the L.-D. bodies in artificial culture, appeared to lend considerable support to the contention. The view, however, of Ronald Ross, expressed in November I903, that the Leishman bodies represented a new genus of parasites and not a species or phase of trypanosome, proved the correct one as time went on. Leishman himself in September 1904 directed attention to the similarity of the flagellate forms found in culture of the L.-D. bodies with the herpetomonas known to be present, for example, in the intestinal tract of the house-fly. Though this interesting connexion of the L.-D. bodies in cultural phase has been kept in view for more than twenty years, it is only within recent months that the problem of transmission seems in a fair way to solution, the most probable insect vector being a species of sand-fly.

Leishman made other important contributions to tropical medicine, particularly in connexion with tick fever and the granular changes which take place in the spirochætes within the body of the tick after an infective feed. The precise significance of these " infective granules " is not yet completely understood.

The association of Leishman with Sir Almroth Wright at Netley in the closing years of the nineteenth and the early years of the twentieth century was the means of introducing him to the great problem of antityphoid vaccination, a measure now so potently

$$
\text { NO. } 2956 \text {, vOL. II } 7 \text { ] }
$$


vindicated by the experience of the War. In 1902 Leishman described a method of estimating quantitatively the phagocytic power of the leucocytes in infection with the view of supplementing the bactericidal tests which had been hitherto mainly employed as criteria of acquired immunity. The technique formed the basis of the method employed by Wright and Douglas (1903) in their analysis of the factors which determine the phagocytosis of micro-organisms in the presence of normal serum. The appointment by the Army Council in March I904 of the Antityphoid Committee " to investigate the practical prophylactic and therapeutic value of current methods of immunisation against enteric fever," gave Leishman and his enthusiastic band of collaborators abundant opportunity for experimental investigation during many busy years. Questions such as the preparation and standardisation of the vaccine, the relative efficiency of vaccines prepared in different ways, their keeping quality, the antibody response to them in the inoculated, and many other cognate questions were submitted to experiment both in man and animals. Thus when the War came, all was en train for the prompt institution of this beneficent preventive measure.

When the War closed, Leishman became the first Director of Pathology at the War Office, a post which he held until his appointment in 1923 to be DirectorGeneral of the Army Medical Service. The influence of Leishman as a teacher and scientific worker was an asset of incalculable value to his corps, and that influence will, we trust, go on to further fruition. The fellowship of the Royal Society came to him in I9ro, and many distinguished orders thereafter. His outside interests were many, and of committee and commission work he took his full share. He was a polished and ready speaker, ever a helpful and courteous colleague, and in his little leisure he found time to indulge his love of art and music and the pleasure of tending his Croydon garden. J. C. G. L.

\section{Sir Frederick MotT, K.B.E., F.R.S.}

Psychiatry has suffered a very grievous loss by the death of Sir Frederick Mott on June 8. To the last he was occupied by his researches, and in spite of advancing years he was a leader of scientific thought in the allied provinces of physiological psychology and psychiatry.

The earlier work of Mott on the physiology of the central nervous system belongs to that period when there was still much to be done by the successors of Fritsch and Hitzig in the field of cortical localisation, and his researches with Schäfer are among the foundations of our knowledge of cerebral physiology. From the motor cortex he turned to the study of sensory represèntation, and his work with Sherrington on the apæsthetic limb was a great contribution to our knowledge of the sensory component of motor activity. His brilliant studies on the anatomy of the spinal encephalic system and the thalamic connexions of the fillet led up to the classical work on the architecture of the cerebral cortex.

Mott's interest in the pathology of the nervous system was determined by his appointment as pathologist to the London County Council Mental Hospitals in 1898 . When working in the Central Laboratory, then situated at Claybury, he had access to the enormous amount of pathological and clinical material furnished by the whole group of London mental hospitals. His first great work in this field was to study the pathology of general paralysis, the one psychosis that was then recognised to be associated obviously with concomitant bodily change. Although the syphilitic origin of general paralysis had been pointed out by KrafftEbbing, this etiology was only accepted by a small minority of psychiatrists in Great Britain. These were the days before the Wassermann reaction, and Mott set himself definitely to prove Krafft-Ebbing's thesis by a close study of a great mass of pathological data and by clinical observations. As a result of his epoch-making research the syphilitic origin of general paralysis was proved beyond all cavil, and this paper was followed by studies on the relation of syphilis to other forms of insanity and to tabes. The whole of this work was published in the first volume of the Archives of Neurology, which he founded.

From his work on general paralysis Mott became firmly impressed by the idea that bodily changes are to be found in all types of psychosis, but he recognised that it was not probable that the functional disturbances of the majority of the psychoses would be shown by the relatively coarse methods of investigation practised in the pathological histology of the nervous system. He turned his attention, therefore, to the bodily mechanisms which exhibited the organic resonance to emotion in the hope that disturbances of the affective states would be sufficiently pronounced at a period of the disease when the higher centres were less affected. Dementia præcox offered the most promising field of study, and in a series of papers on the pathology of the gonads and other endocrine organs and the vegetative nervous system in this disease, he was able to demonstrate with certainty the existence of a widespread degenerative change preceding the far slighter evidences of degeneration that could be detected in the central nervous system in advanced cases. In other psychoses similar though less marked pathological changes were encountered. Mott, however, was a profound disbeliever in the attempts to relegate the psychoses into sharply-defined classes. $\mathrm{He}$ considered that though the signs of structural impairment were most obvious in dementia præcox, there was not clinically or pathologically any hard-and-fast line between this and other psychoses. He was well aware that the methods of pathological anatomy could only furnish evidences of relatively gross changes, and he turned to the study of the biochemistry and physics of the central nervous system.

Though Mott later greatly modified the conclusions that he drew from the attempts which he made with Halliburton to demonstrate the existence of products of nervous degeneration in the cerebral spinal fluid, this work, which he published in his Croonian Lectures, was important as the starting-point of many subsequent investigations into the chemical pathology of the nervous system.

As a consultant neurologist to a clearing hospital for war neuroses Mott's attention was diverted for a time from the psychoses to the neuroses. A study of the previous

NO. 2956, VOL. I I 7$\rceil$ 